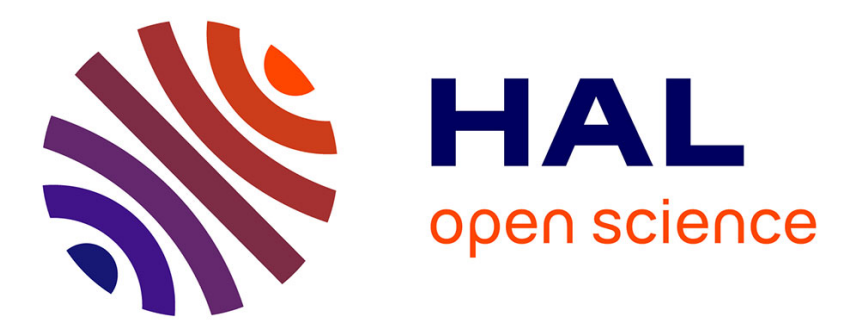

\title{
Influence of UV grafting conditions and gel formation on the loading and stabilization of palladium nanoparticles in photografted polyethersulfone membrane for catalytic reactions
}

\author{
Clélia Emin, Jean-Christophe Remigy, Jean-Francois Lahitte
}

\section{To cite this version:}

Clélia Emin, Jean-Christophe Remigy, Jean-Francois Lahitte. Influence of UV grafting conditions and gel formation on the loading and stabilization of palladium nanoparticles in photografted polyethersulfone membrane for catalytic reactions. Journal of Membrane Science, 2014, vol. 455, pp. 55-63. 10.1016/j.memsci.2013.12.049 . hal-01286151

\section{HAL Id: hal-01286151 \\ https://hal.science/hal-01286151}

Submitted on 10 Mar 2016

HAL is a multi-disciplinary open access archive for the deposit and dissemination of scientific research documents, whether they are published or not. The documents may come from teaching and research institutions in France or abroad, or from public or private research centers.
L'archive ouverte pluridisciplinaire HAL, est destinée au dépôt et à la diffusion de documents scientifiques de niveau recherche, publiés ou non, émanant des établissements d'enseignement et de recherche français ou étrangers, des laboratoires publics ou privés. 


\section{OATAO}

\section{Open Archive TOULOUSE Archive Ouverte (OATAO)}

OATAO is an open access repository that collects the work of Toulouse researchers and makes it freely available over the web where possible.

This is an author-deposited version published in : http://oatao.univ-toulouse.fr/ Eprints ID : 15580

To link to this article : DOI:10.1016/j.memsci.2013.12.049

URL : http://dx.doi.org/10.1016/j.memsci.2013.12.049

To cite this version : Emin, Clélia and Remigy, Jean-Christophe and Lahitte, Jean-Francois Influence of UV grafting conditions and gel formation on the loading and stabilization of palladium nanoparticles in photografted polyethersulfone membrane for catalytic reactions. (2014) Journal of Membrane Science, vol. 455. pp. 55-63. ISSN 03767388

Any correspondence concerning this service should be sent to the repository administrator: staff-oatao@,listes-diff.inp-toulouse.fr 


\title{
Influence of UV grafting conditions and gel formation on the loading and stabilization of palladium nanoparticles in photografted polyethersulfone membrane for catalytic reactions
}

\author{
Clélia Emin $^{\mathrm{a}, \mathrm{b}}$, Jean-Christophe Remigy ${ }^{\mathrm{a}, \mathrm{b}}$, Jean-François Lahitte ${ }^{\mathrm{a}, \mathrm{b}, *}$ \\ a Université de Toulouse, INPT, UPS, Laboratoire de Génie Chimique, F-31062 Toulouse Cedex 09, France \\ ${ }^{\mathrm{b}}$ CNRS, Laboratoire de Génie Chimique, F-31062 Toulouse Cedex 09, France
}

Keywords:

Hollow fiber membrane

UV photografting

Functionalization

Palladium nanoparticles

Catalytic membrane reactor

\begin{abstract}
A B S T R A C T
This paper reports innovative coupling for the development of catalytic membrane reactors. Photografting for the modification of membrane surfaces has been extensively studied and we used the results to optimize metal nanoparticle loading. Polyethersulfone hollow fibers were modified by poly(acrylic acid) grafting and the impact of a cross-linked network and a polymer gel grafted layer on metal loading was examined. Transmission electron microscopy images showed well dispersed metal nanoparticles close to the surface. The catalytic activity of the different hollow fibers was assessed by the reduction of pnitrophenol into p-aminophenol and a conversion yield of close to $100 \%$ was found. We demonstrated the possibility of obtaining various reactors by varying the residence time through alteration of the grafted layer.
\end{abstract}

\section{Introduction}

Polymers have been widely studied in order to modify their properties. Various techniques such as blending, coating or chemical modifications have been successfully developed during the last decade [1-3]. UV irradiation graft polymerization is one of these techniques [4,5], which presents many advantages including low energy costs, simplicity and cleanliness of the method and long-term chemical stability [6]. In membrane science, this technique has mainly been reported for the reduction of fouling on various polymer membranes [7,8]. Polyethersulfone (PES) membranes are widely used in water treatment and are well known for their mechanical strength, thermal and chemical stability. Moreover, the advantage of poly(arylsulfone) membranes is their intrinsic photosensitivity to UV irradiation provided by the phenoxyphenyl sulfone chromophore in the backbone of the polymer chain leading to the production of free radicals $[9,10]$. In the presence of vinyl monomers, e.g. acrylic acid, grafting occurs with covalent bonds being formed between the membrane support and graft chains [11]. The grafted chains remain at the surface without affecting the bulk properties. Thus, with this technique, it is

\footnotetext{
* Correspondence to: Laboratoire de Génie Chimique, Université Paul Sabatier, 31062 Toulouse Cedex 09, France. Tel.: +33561556829.

E-mail address: lahitte@chimie.ups-tlse.fr (J.-F. Lahitte).
}

possible to obtain various specific surface properties depending on the nature of the monomers.

Currently, a great interest is focused on nano-scale materials due to their unique properties (e.g. high specific surface areas, special optical properties) that differ from those of the bulk material. More specifically, metal nanoparticles (MNP) such as those of platinum group metals are considered as an interesting choice for catalytic reactions [12]. In the nanoparticle state, palladium is well known to have the ability to adsorb hydrogen into its lattice and dissociate it. The unique affinity of this metal towards hydrogen makes it a good catalyst for various hydrogenation reactions [13]. However, without stabilizing agents such as polymers or surfactants [14], nanoparticles tend to agglomerate in solution forming aggregates and thus reducing their high efficiency. The functionalization of membrane surfaces with charged groups can stabilize nanoparticles in the polymeric matrix [15]. These functional groups are able to retain metal ion nanoparticle precursors. Once the precursor is immobilized at the membrane surface, MNP can grow by chemical reduction of metal ions. MNP thus become stabilized inside the grafted layer.

Modified membranes can then be used for an innovative application in terms of water depollution. Currently, water treatment is ineffective for many polluting molecules like pesticides or endocrine disruptors. These compounds are a major concern due their high toxicity in groundwater and drinking water and a combination of traditional membrane processes and catalysis could be an opportunity to deal with them. Catalytic membrane 
reactors (CMR) containing MNP can perform the reaction and separation steps simultaneously in the same unit. However, the very low concentrations of the target molecules and the toxicity of the by-products can affect the viability of such processes. In the chemical industry, membrane processes involving catalysts can be an alternative to the synthesis of chemical compounds. For example, Astruc [16] mentions numerous reactions catalyzed by transition metal nanoparticles. However, the use of nanoparticles in reactors such as fluidized beds involving cohesion forces could lead to aggregation of the nanoparticles [17] due to interaction forces such as London-van der Waals or electrostatic interactions. Additionally, recovery of the nanoparticles in a continuous process could pose further problems. Catalytic membrane reactors appear to offer good prospects to overcome these limitations, especially with MNP.

Research with various membrane modifications for the stabilization of MNP in the polymer matrix have already shown good results. Ouyang et al. [18] reported the catalytic reduction of 4-nitrophenol with $\mathrm{NaBH}_{4}$ using catalytic hollow fiber membranes prepared using layer-by-layer polyelectrolyte deposition and gold nanoparticles. Smuleac et al. [19] effectively modified poly(vinylidene fluoride) (PVDF) by in situ polymerization of acrylic acid for dechlorination applications. This functionalized membrane contained $\mathrm{Fe}$ or core-shell $\mathrm{Fe} / \mathrm{Pd}$ nanoparticles formed by reduction with $\mathrm{NaBH}_{4}$. Domènech et al. [20] used polymeric membranes made with sulfonated PES (PESCardo) and nanoparticles were prepared using an intermatrix synthesis methodology. The catalytic activity of the reduction of p-nitrophenol has also been studied with Pt nanoparticles in a thin film of poly (2-vinylpyridine) [21].

In a previous paper [22], we already demonstrated the feasibility of stabilizing MNP in a grafted polymer. In the present work, we studied the impact on stabilized noble nanoparticles of modifying hollow fiber by photografting. The catalytic activity of the different membranes obtained was assessed. The influence of the nature and the thickness of graft chains was studied on palladium loading and on the reactivity of the nanoparticles. The catalytic performance of the membranes was evaluated by the reduction of p-nitrophenol to p-aminophenol. p-Nitrophenol, which is produced during the synthesis of paracetamol, is frequently used as a model pollutant. Reactions were performed in two different configurations [23]: flow through membrane contactor and in a batch reactor for comparison.

\section{Materials and methods}

\subsection{Materials}

Microfiltration PES hollow fibers MicroPES ${ }^{\circledR}$ were purchased from Membrana (Wuppertal, Germany). This membrane has a nominal pore size of $0.2 \mu \mathrm{m}$, an inner diameter of $300 \mu \mathrm{m}$ and a wall thickness of $100 \mu \mathrm{m}$. Sodium p-styrene sulfonate, acrylic acid, N,N'-methylenebisacrylamide, 4-hydroxybenzophenone, sodium chloride, sodium borohydride, tetraamminepalladium (II) chloride monohydrate, toluidine blue $\mathrm{O}$ and p-nitrophenol were purchased from Sigma Aldrich (France). Sodium hydroxide, hydrochloric acid and acetic acid were purchased from Carlo Erba (France) and nitric acid from VWR (France). All compounds were used without further purification and solutions were prepared with deionized water.

\subsection{Methods}

\subsubsection{Functionalization of hollow fiber surface by photografting polymerization}

Hollow fibers were functionalized using a continuous UV photografting polymerization setup already described in a previous paper
[24] with slight modification. Before the polymerization process, membranes were water-soaked to prevent overheating of the fiber. The membranes were then dipped into a monomer solution containing acrylic acid (AA) as monomer, 4-hydroxybenzophenone as photoinitiator and $\mathrm{N}_{\mathrm{N}} \mathrm{N}^{\prime}$-methylenebisacrylamide as cross-linker. The photoinitiator ensured the creation of free radicals and the crosslinker ensured formation of a polymer network. The concentration of AA was 15 wt\% and 25 wt\% in water. Concentrations of cross-linker and photoinitiator are expressed in mol\% of monomer. The membrane was passed through two industrial UV polychromatic lamps (UVAPRINT LE, doped halogen lamps, $I=5520-10,080 \mathrm{~mW} \mathrm{~cm}^{-2}$, Hoenle UV France, Lyons, France). The operating rate was adjusted to between 8 and $20 \mathrm{~m} \mathrm{~min}^{-1}$, corresponding to an irradiation time (IRT) of between 3.75 and $1.50 \mathrm{~s}$. The filter was made of quartz. In our conditions, the thickness of the liquid film coating was determined by the Landau and Levich equation [25] and the mode of entrainment characterized by a visco-inertial mode as demonstrated by GomaBilongo et al. [26] in a numerical simulation of the photografting setup. For this series of experiments, the hollow fiber was irradiated in the first lamp in order to create radicals at the surface. The experiment was performed under nitrogen atmosphere as oxygen is an inhibitor for the polymerization $[27,28]$. Then, the fiber was passed through the monomer solution and polymerization took place under the second lamp. After grafting, all membranes functionalized with carboxylic groups $\left(-\mathrm{COO}^{-} \mathrm{H}^{+}\right)$were washed with, and subsequently stored in, deionized water to remove excess monomer and any homopolymer not covalently bound to the membrane. The water flux was measured on pristine and grafted membranes in dead-end filtration mode using laboratory-made modules. The structure and the thickness of the grafted polymer of membranes washed then dried in an oven for several days were determined under a scanning electron microscope (SEM, TM-1000 Tabletop Microscope, Hitachi). Surface analysis of membranes was performed by attenuated total reflection Fourier transform infrared spectroscopy (ATR-FTIR, Thermo-Nicolet Nexus 670). The nominal incident angle was $45^{\circ}$ and all spectra were recorded at $25{ }^{\circ} \mathrm{C}$. The weight of grafting was determined using the Toluidine Blue O (TBO) colorimetric method described by Michiardi et al. [29]. Each measurement was repeated three times.

\subsubsection{Palladium nanoparticle synthesis in the functionalized PES membranes}

The synthesis of nanoparticles was carried out using the Intermatrix synthesis method [30]. Membranes were immerged at room temperature in a $0.02 \mathrm{M}$ solution of palladium salt [Pd $\left(\mathrm{NH}_{3}\right)_{4} \mathrm{Cl}_{2} \cdot \mathrm{H}_{2} \mathrm{O}$ ] overnight in order to achieve complete ionexchange between protons on the grafted layer and the palladium complex $\left[\mathrm{Pd}\left(\mathrm{NH}_{3}\right)_{4}\right]^{2+}$ according to Eq. (1). Palladium nanoparticles were then formed on reduction of the $\mathrm{Pd}^{2+}$ following immersion of the membrane in a $0.1 \mathrm{M}$ aqueous solution of $\mathrm{NaBH}_{4}$. Formation of the nanoparticles shifts the ion exchange equilibrium in Eq. (2) to the right since $\mathrm{Pd}^{2+}$ cations are consumed to form $\mathrm{Pd}^{0}$ [31]. Consequently, intermatrix synthesis enables the ionogenic functions, leading to another cycle of metal exchange and reduction which further increases metal loading.

$$
\begin{aligned}
& 2 \mathrm{R}-\mathrm{COO}^{-} \mathrm{H}^{+}+\left[\mathrm{Pd}\left(\mathrm{NH}_{3}\right)_{4}\right]^{2+} \rightarrow\left(\mathrm{R}-\mathrm{COO}^{-}\right)_{2}\left[\mathrm{Pd}\left(\mathrm{NH}_{3}\right)_{4}\right]^{2+}+2 \mathrm{H}^{+}(1) \\
& (\mathrm{R}-\mathrm{COO}-)_{2}\left[\mathrm{Pd}\left(\mathrm{NH}_{3}\right)_{4}\right]^{2+}+2 \mathrm{Na}^{+} \rightarrow 2 \mathrm{R}^{-} \mathrm{COO}^{-} \mathrm{Na}^{+}+\left[\mathrm{Pd}\left(\mathrm{NH}_{3}\right)_{4}\right]^{2+}(2) \\
& {\left[\mathrm{Pd}\left(\mathrm{NH}_{3}\right)_{4}\right]^{2+}+2 \mathrm{BH}_{4}{ }^{-}+6 \mathrm{H}_{2} \mathrm{O} \rightarrow \mathrm{Pd}^{0}+7 \mathrm{H}_{2}+2 \mathrm{~B}(\mathrm{OH})_{3}+4 \mathrm{NH}_{3}}
\end{aligned}
$$

In order to evaluate the effects of $\mathrm{pH}$ on ion exchange equilibrium, a set of poly(acrylic acid) (PAA) grafted membranes were immersed in a solution of sodium chloride $(5.2 \mathrm{M})$ at $\mathrm{pH} 10$ for at least $6 \mathrm{~h}$ prior to ion exchange with the palladium salt to convert $-\mathrm{COO}^{-} \mathrm{H}^{+}$to the $-\mathrm{COO}^{-} \mathrm{Na}^{+}$form as described by Smuleac et al. [19]. 


\subsubsection{Quantification of palladium}

Palladium loading of the membrane was determined by inductively coupled plasma optical emission spectrometry (ICP-OES, Ultima 2, Horoba Jobin Yvon). $1 \mathrm{~cm}^{2}$ of membrane sample was dissolved in aqua regia and diluted in water. This diluted solution was analyzed using ICP. Measurements were repeated three times using different membrane samples on different positions along the hollow fibers. The palladium concentration in permeates was also determined in order to quantify leaching during filtration.

\subsubsection{Characterization of palladium nanoparticles}

The presence of Pd was confirmed by energy-dispersive X-ray spectroscopy (EDX) analysis. Images of nanoparticles were obtained by transmission electron microscopy (TEM, JEOL Jem 1400). Samples of membranes were first embedded in resin and then thin slides were cut with a microtome. The analyses provided the size and the distribution of the MNP.

\subsubsection{Catalytic conversion of p-nitrophenol}

The catalytic reduction of p-nitrophenol to p-aminophenol was performed in the presence of sodium borohydride solution $\left(\mathrm{NaBH}_{4}\right)$ in convection mode and batch reactor. In the batch reactor system, $8.6 \mathrm{~cm}^{2}$ of membrane were immersed in $40 \mathrm{ml}$ of a mixture of p-nitrophenol $(0.72 \mathrm{mM})$ and $\mathrm{NaBH}_{4}(14.38 \mathrm{mM})$. We assumed that the carefully mixed solution was homogeneous and only small samples were taken in order to keep the reaction volume almost constant. In flow through membrane configuration, a solution containing p-nitrophenol and $\mathrm{NaBH}_{4}$, at the same concentration, was filtered across the membrane at room temperature using hollow fiber modules containing two fibers corresponding to a total surface area of $8.6 \mathrm{~cm}^{2}$. The reducing compound was in excess $(20: 1)$, so the kinetics of the reduction could be assimilated to a pseudo first order reaction. The concentration of p-nitrophenol was monitored by UV-visible spectrometry ( $\lambda=400 \mathrm{~nm}$, Uvilight, XTD5) versus time in order to follow the conversion.

\section{Results and discussion}

\subsection{UV-induced membrane modification}

As demonstrated in previous articles [2,4], UV photografting polymerization is an efficient method to modify a polymeric membrane surface. Fig. 1 clearly shows that altering the radiation energy received by the membrane surface (determined by the irradiation time and the power supply of the UV lamp) modifies the weight of polymer grafted onto the membrane surface. The greater the energy received by the membrane the greater the weight of polymer grafted. Three zones, with different slopes on the plot can be identified in Fig. 1. In the first zone from 0 to $12.3 \mathrm{~J} \mathrm{~cm}^{-2}$, the energy is mostly consumed by the inhibitor/ oxygen present in the monomer solution (used without purification). After this induction time, all the inhibitor is destroyed and the dissolved oxygen consumed thus the weight polymer grafted rises almost linearly with the received energy from 12.3 to $21.4 \mathrm{~J} \mathrm{~cm}^{-2}$. Then, for energies higher than $21.4 \mathrm{~J} \mathrm{~cm}^{-2}$, the evolution tends to become asymptotic. This result is in agreement with the observation of Goma-Bilongo et al. [26] who determined, by modeling that a total consumption of the monomer occurred for high energies received by the membrane, maximizing the amount of polymer grafted.

The pure water flux of the grafted membranes decreases with the weight of grafted polymer to reach almost zero for $0.55 \mathrm{~g} \mathrm{~m}^{-2}$ grafting. Grafting reduces pore size and thus decreases

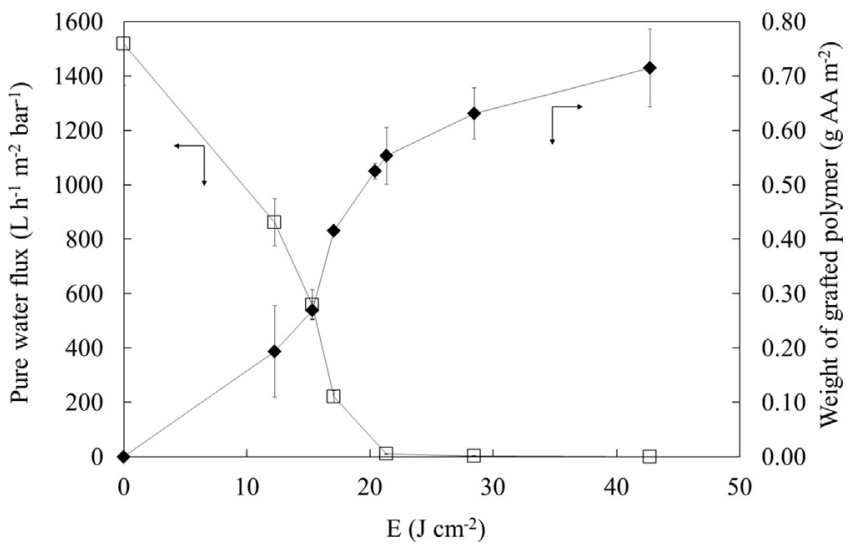

Fig. 1. Weight of grafted poly(acrylic acid) on membrane surface (diamond) and pure water flux (square) as a function of UV irradiation energy received by the membrane. $[\mathrm{AA}]=25 \mathrm{wt} \%,[\mathrm{PI}]=0.03 \mathrm{~mol} \%$, [cross-linker $]=2.7 \mathrm{~mol} \%$.

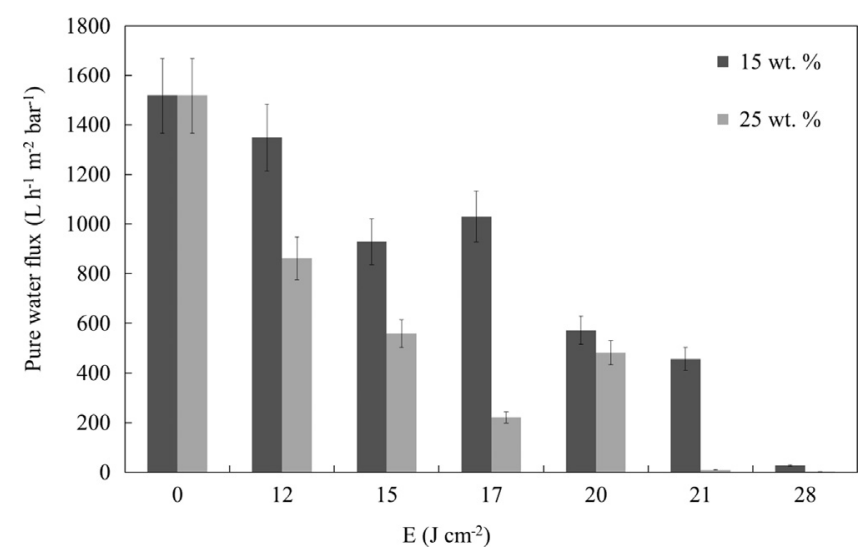

Fig. 2. Permeability versus UV irradiation energy received by the membrane for 2 concentrations of acrylic acid. $[\mathrm{AA}]=15 \mathrm{wt} \%$ and $25 \mathrm{wt} \%,[\mathrm{PI}]=0.03 \mathrm{~mol} \%$, [crosslinker] $=2.7 \mathrm{~mol} \%$.

permeability. No permeability decrease was observed with a pristine membrane irradiated in the same conditions but without reactant, indicating that, in our conditions, UV radiation did not degrade the membrane surface significantly and mass transfer properties were maintained. Permeability is plotted versus energy received by the membrane for different concentrations of $15 \mathrm{wt} \%$ and 25 wt\% AA (Fig. 2). For both AA concentrations, a similar trend was found but with $15 \mathrm{wt} \%$ the permeability reached zero for a higher energy $\left(28.5 \mathrm{~J} \mathrm{~cm}^{-2}\right)$.

ATR-FTIR analysis was used to examine the change in the chemical composition of hollow fiber surface and to confirm the presence of grafted polymer. Fig. 3 shows spectra for pristine PES hollow fiber and different weights of PAA grafted onto membranes. The two bands at 1578 and $1486 \mathrm{~cm}^{-1}$ are characteristic of the aromatic rings of PES. In the region below $3000 \mathrm{~cm}^{-1}$, the two bands at 3060 and $3049 \mathrm{~cm}^{-1}$ are attributed to aromatic C-H vibration of the membrane support. The analysis performed on grafted PAA hollow fibers showed a new absorption band at $1702 \mathrm{~cm}^{-1}$ corresponding to the stretching of the carboxylic group $(\mathrm{C}=\mathrm{O})$ of PAA. The intensity of this band increased with the weight of grafted polymer, as seen from the spectra of modified membranes (b)-(d) indicating an increase of functionalized groups (Table 1). Below $2700 \mathrm{~cm}^{-1}$ a broad peak corresponds to the asymmetric vibration of $\mathrm{O}-\mathrm{H}$ stretching for the grafted membranes (not visible on pristine PES). Although the membranes were dried in 


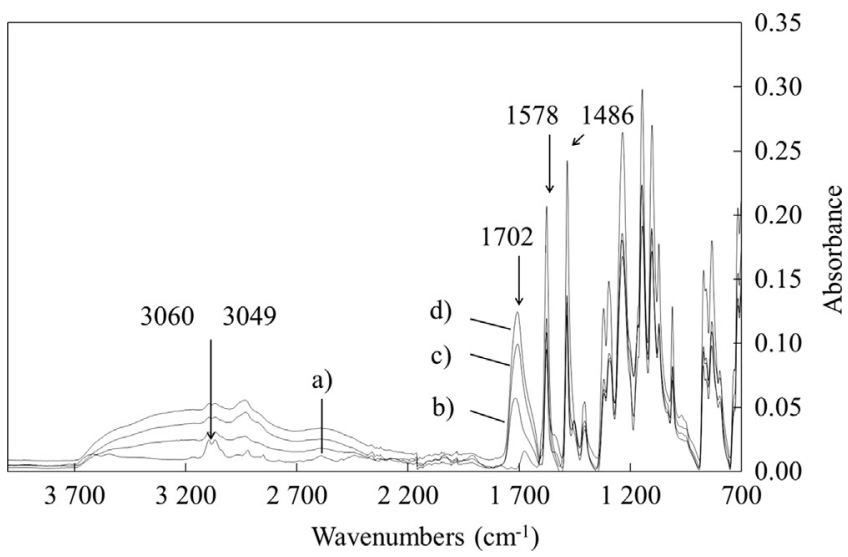

Fig. 3. ATR-FTIR spectra of (a) pristine PES, (b) PES-PAA1, (c) PES-PAA2 and (d) PESPAA3.

Table 1

Weight and thickness of the grafted poly(acrylic acid) layer determined by TBO analysis and SEM images; $[\mathrm{AA}]=25 \mathrm{wt} \%,[\mathrm{PI}]=0.03 \mathrm{~mol} \%$, [cross-linker $]=2.7 \mathrm{~mol} \%$.

\begin{tabular}{lcll}
\hline Membrane & $\begin{array}{l}E \\
\left(\mathrm{~J} \mathrm{~cm}^{-2}\right)\end{array}$ & $\begin{array}{l}\text { Weight of grafted polymer } \\
\left(\mathrm{g} \mathrm{AA} \mathrm{m}^{-2}\right)\end{array}$ & $\begin{array}{l}\text { Thickness of the grafted } \\
\text { polymer }(\mu \mathrm{m})\end{array}$ \\
\hline PES & 0 & - & - \\
PES-PAA1 & 12.3 & $0.19 \pm 0.01$ & $0.7 \pm 0.1$ \\
PES-PAA2 & 15.3 & $0.27 \pm 0.02$ & $0.8 \pm 0.1$ \\
PES-PAA3 & 17.1 & $0.42 \pm 0.05$ & $1.2 \pm 0.1$ \\
PES-PAA4 & 20.4 & $0.53 \pm 0.08$ & $1.7 \pm 0.1$ \\
PES-PAA5 & 21.3 & $0.55 \pm 0.05$ & $2.2 \pm 0.1$ \\
PES-PAA6 & 28.5 & $0.63 \pm 0.01$ & $3.2 \pm 0.1$ \\
PES-PAA7 & 42.7 & $0.72 \pm 0.07$ & $3.6 \pm 0.1$ \\
PES-PAA8 & 20.4 & $0.27 \pm 0.12$ & $0.8 \pm 0.1$ \\
\hline
\end{tabular}

${ }^{\mathrm{a}}[\mathrm{AA}]=15 \mathrm{wt} \%,[\mathrm{PI}]=0.03 \mathrm{~mol} \%$, and $[$ cross-linker $]=2.7 \mathrm{~mol} \%$.

an oven, these bands could be due to the water molecules trapped in the PAA network and bound to the hydrophilic hydroxyl groups.

After a certain degree of grafting corresponding to a grafted layer of $2.2 \mu \mathrm{m}$, the PES signal became unclear resulting from a total coating of the membrane surface.

Membranes were studied by SEM to visualize surface modifications and to estimate the thickness of the grafted layer. Thicknesses of the grafted polymer layer are reported in Table 1.

It can be seen in the SEM pictures (Fig. 4) that grafted polymer formed an interpenetrating layer with the pristine membrane at the membrane surface. This layer may partially then completely obstruct pores present at the surface. It thus increases the total membrane resistance to the water flux leading to a loss of permeability.

As shown in Fig. 4, the pores disappear and the surface becomes smoother leading to a dramatic change in the appearance of the surface with an increase of the degree of grafting. The cross section allows the grafted polymer layer (indicated by the arrow on the picture) to be clearly distinguished and its thickness measured. It appears uniform and dense (see Table 1).

The thickness of the grafted layer was plotted versus the weight of grafted polymer (Fig. 5). As expected, the thickness of the layer increased with the weight of grafted polymer. However, the variation was not linear and after $0.53 \mathrm{~g} \mathrm{AA} \mathrm{m}^{-2}$ the slope became steeper. The theoretical thickness of the corresponding dense polymer layer can be calculated from the weight of grafted polymer assuming the density of the grafted PAA to be equal to that of pure dense PAA. This calculated thickness was significantly lower than the measured one indicating that the grafted layer is porous. The calculated porosity (defined here as the ratio thickness of polymer layer/thickness of equivalent dense layer) increased with the degree of grafting and two porosities were observed: for a degree of grafting below $0.53 \mathrm{~g} \mathrm{AA} \mathrm{m}^{-2}$, the calculated porosity was around 0.7 (as seen on the calculated thickness for a porosity of 0.7 ) whereas above $0.65 \mathrm{~g} \mathrm{AA} \mathrm{m}^{-2}$ the calculated porosity was around 0.8 .

The use of a cross-linker during the polymerization leads to formation of a polymer network. The hydrated 3D polymer network formed can then collapse during the drying step before microscopy. This phenomenon will depend on the degree of crosslinking. In the experimental conditions used the degree of crosslinking increased with the UV energy received by the membrane. At low UV energy, polymerization was incomplete and the polymer layer only partially cross-linked. For a higher UV energy, the degree of polymerization increased and the gelling point was crossed. A chemical gel was obtained. This leads to two different kinds of layer, a partially cross-linked polymer and a chemical polymer gel. After drying, both layers be porous but the less crosslinked one will collapse more than the gel leading to a lower porosity, as observed.

The formation of a grafted layer at the membrane surface leads to a decrease of membrane permeability. This decrease is due to greater resistance to water transfer and to smaller pore diameters, the pores being progressively blocked by the grafted layer of hydrated cross-linked polymer (Fig. 6).

\subsection{Palladium nanoparticle synthesis in the functionalized PES membranes}

As shown in Fig. 7, palladium loading increased with the amount of grafted polymer. Measured values were higher than those theoretically expected for stoichiometric ion exchange between $\mathrm{Pd}^{2+}$ and polyelectrolyte counter ions. We observed a large increase in palladium loading after $7 \mathrm{meq} \mathrm{m}^{-2}$ of grafted PAA due to the transition of the polymer layer structure from partially cross-linked to a chemical polymer gel. As seen in Fig. 5, the chemical polymer gel is more porous than the partially crosslinked layer, allowing easier access of the $\mathrm{Pd}^{2+}$ to polymeric charge. This porous volume can also sterically entrap $\mathrm{Pd}^{2+}$ solution without need of a specific charge effect.

Pre-treating grafted membranes with a concentrated solution of sodium chloride facilitated the ion exchange capacity which slightly increased the Pd loaded into the membrane (cross sign).

The results show that Pd nanoparticles can also be synthesized in a pristine membrane without any grafting at the surface, certainly due to limited adsorption of Pd salt at the membrane surface. However, the amount of Pd included in this condition is significantly lower (1.7 meq Pd $\mathrm{m}^{-2}$ ).

TEM analysis confirmed the nanoparticle state of the Pd ${ }^{\circ}$. Fig. 8 shows a cross section of hollow fibers analyzed by TEM. The first image corresponds to the pristine PES membrane and the other is an example of PAA grafted membrane (PES-PAA5). In the figures, arrows show the external surface of the membrane. It appears that the grafted layer can also be clearly seen by TEM images. A higher magnification of the square zone is shown in Fig. 9. The palladium detected in the pristine membrane was found to mainly occur as nanoparticles but aggregates are also clearly visible. In grafted membranes, the size of the particles was found to be smaller than $5 \mathrm{~nm}$. The nanoparticles were clearly located in the grafted polymer layer, at the surface of the membrane, homogeneously and without noticeable aggregation.

In all experiments, a second loading increased the concentration of metal (Table 2). The TEM analyses, reported in Fig. 10, demonstrate the effective incorporation of an additional quantity of palladium after this second cycle. TEM observation indicated that the average diameter of nanoparticles increased from 4.7 to 

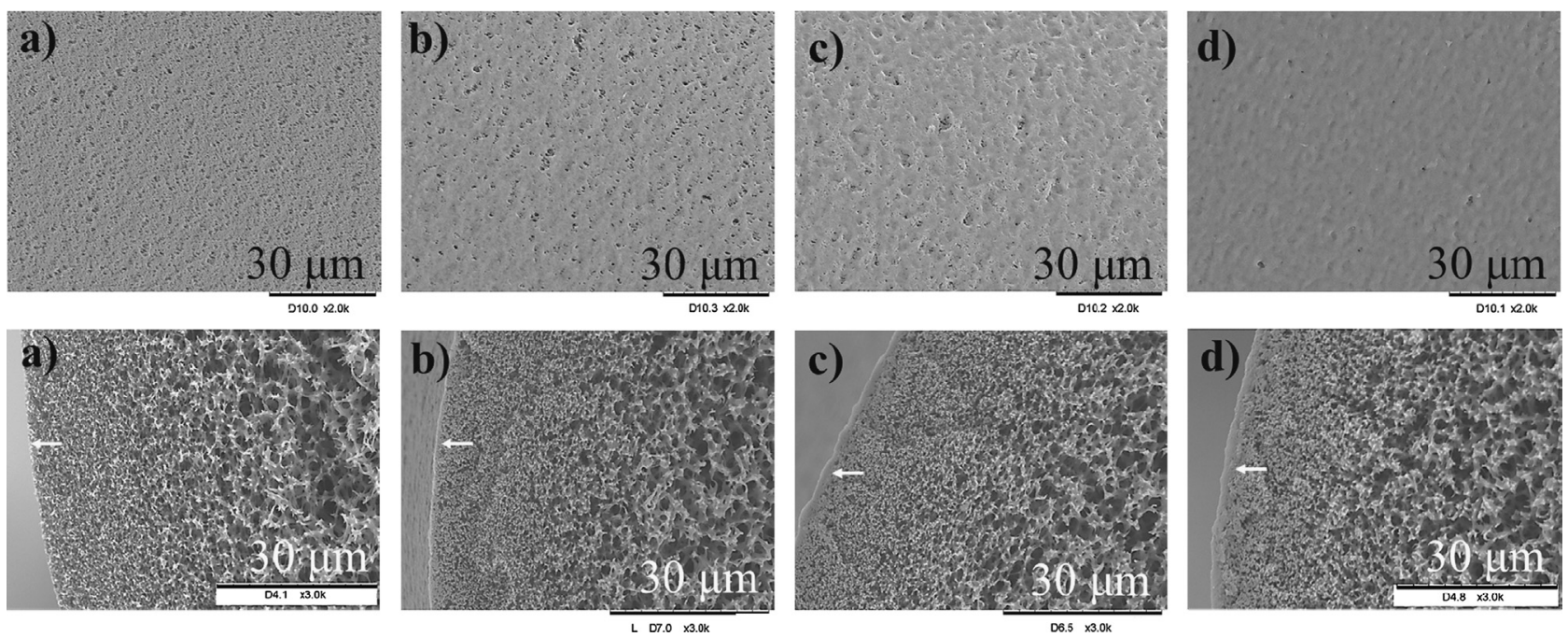

Fig. 4. SEM images of surface membranes (top) and cross sections (bottom) for (a) pristine PES hollow fiber, (b) PES-PAA2, (c) PES-PAA4 and (d) PES-PAA5.

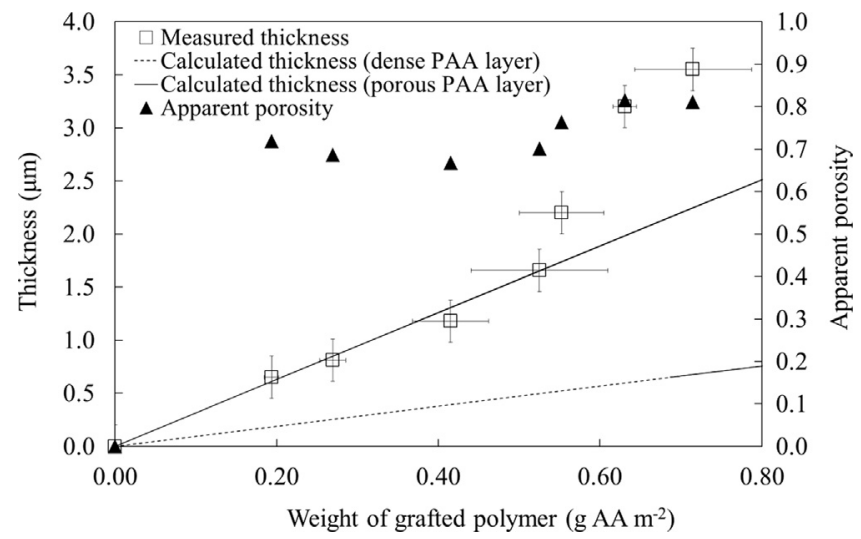

Fig. 5. Thickness and apparent porosity of the polymer film grafted on the membrane versus the weight of grafted polymer.

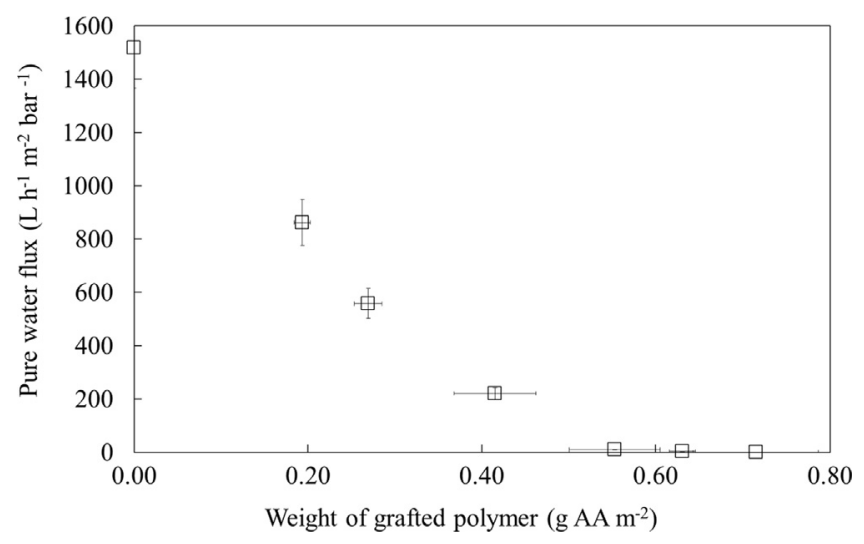

Fig. 6. Pure water flux of the different grafted membranes versus the weight of grafted polymer.

$8.4 \mathrm{~nm}$ corresponding to a drop in specific surface area from 106 to $59 \mathrm{~m}^{2} \mathrm{~g}^{-1}$. For single loading, the weighted mean diameter calculated as a function of the percentage frequency with $1 \mathrm{~nm}$ intervals tends to a Gaussian distribution (white diamonds). The average diameter (for a second loading) was higher than the values obtained for the heterogeneous primary nucleation. The distribution shifted to the right due to favorable secondary nucleation kinetics. Thus, the first nanoparticles incorporated in

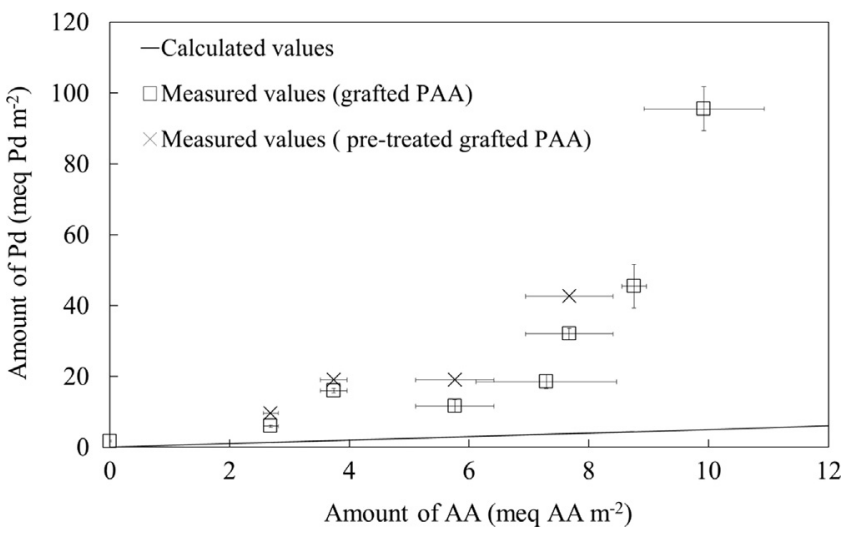

Fig. 7. Palladium loading versus the amount of poly(acrylic acid) grafted to the membranes, with (cross sign) and without (square sign) pre-treatment of the membrane with $\mathrm{NaCl}$.

the membrane act as precursors for the second load, as described for "core-shell" nanoparticle synthesis. No or few new particles were created. The average diameter calculated from the number of particles generated during a primary nucleation and the actual Pd loading for a second cycle was around $6.8 \mathrm{~nm}$, lower than the measured one. However, this value is within the margin of error.

\subsection{Leaching of MNP}

One of the many advantages of catalytic membranes is that as the catalyst is supported by the membrane, it does not have to be removed from the solution at the end of the process. The leaching of MNP incorporated inside the membrane was determined in order to ascertain if MNP were well trapped in the grafted layer. This conditions the viability of the process. Deionized water was filtered through the membrane, at constant pressure of 0.1 bar and the permeate was analyzed by ICP. We found a concentration in the permeate below the limit of quantification (LOQ), $15 \mathrm{ppb}$. Thus, the values shall only be expressed qualitatively. The concentration detected was slightly above the limit of detection (LOD), $3 \mathrm{ppb}$, indicating leaching close to zero. These low values for pristine and grafted membrane indicate that no leaching occurred in our membranes i.e. the MNP present inside the membrane were stabilized and well secured. 

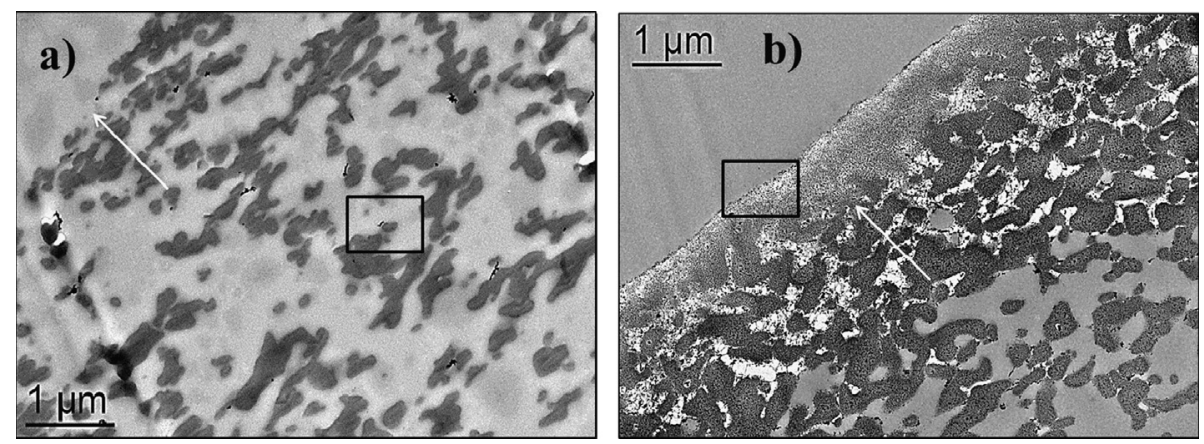

Fig. 8. TEM images of (a) pristine polyethersulfone and (b) poly(acrylic acid) grafted membrane (PES-PAA5).
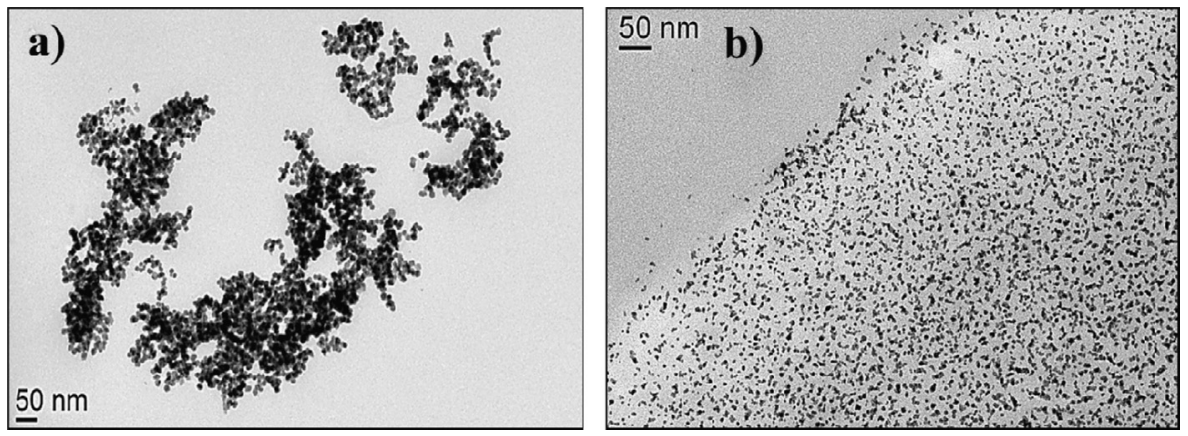

Fig. 9. TEM images of (a) aggregate in pristine polyethersulfone and (b) external cross section of poly(acrylic acid) grafted membrane (PES-PAA5).

Table 2

Palladium load for PAA grafted membranes for a single and for a second loading.

\begin{tabular}{llll}
\hline Membrane & $\begin{array}{l}\text { Weight of grafted polymer } \\
\left(\mathrm{g} \mathrm{m}^{-2}\right)\end{array}$ & $\begin{array}{l}\text { "Single loading" } \\
\text { Pd load } \\
\left(\mathrm{mg} \mathrm{cm}^{-2}\right)\end{array}$ & $\begin{array}{l}\text { "Second } \\
\text { loading" } \\
\left(\mathrm{mg} \mathrm{cm}^{-2}\right)\end{array}$ \\
\hline PES & - & $0.009 \pm 0.001$ & $0.030 \pm 0.003$ \\
PES-PAA1 & $0.19 \pm 0.01$ & $0.032 \pm 0.002$ & $0.065 \pm 0.003$ \\
PES-PAA3 & $0.42 \pm 0.05$ & $0.062 \pm 0.009$ & $0.183 \pm 0.011$ \\
\hline
\end{tabular}

\subsection{Catalytic reduction of p-nitrophenol}

The reduction of p-nitrophenol into p-aminophenol is described by a Langmuir-Hinshelwood mechanism [32]. After a certain reaction time, the solution changes color, turning from yellow to colorless for total conversion, indicating the complete reduction of the nitrophenol. Moreover, for all essays, the absorbance of p-aminophenol was followed at $297 \mathrm{~nm}$ and a decrease of the p-nitrophenol peak was found to occur concomitantly with an increase of the p-aminophenol peak, indicating the reduction of the substrate. Thus, conversion was expressed as absorbance of p-nitrophenol.

In the experiment, sodium borohydride was used is excess, thus the apparent kinetic constant $k_{a p p}$ is defined by

$\frac{d C_{R N O_{2}}}{d t}=-k_{a p p} C_{R N O_{2}}$

where $k_{\text {app }}$ is the apparent kinetic constant and $C_{\mathrm{RNO}_{2}}$ is the concentration of p-nitrophenol.

\subsubsection{Batch reactor}

In batch reactor conditions for a reaction with first order kinetics, plotting $\mathrm{C}_{\mathrm{RNO}_{2}}$ versus time gives access to the kinetic constant $k_{\text {app }}$.

$C_{R N O_{2}}=C_{R O_{2}}^{0} \exp \left(-k_{a p p} t\right)$

where $C_{\mathrm{RNO}_{2}}^{0}$ is the initial concentration of p-nitrophenol and $t$ is the time.

To take into account the palladium loading of the membranes, the apparent kinetic constant $k_{\text {app }}$ was defined as a new constant $k$ corresponding to the ratio $k_{a p p} /$ mass of Pd. Experiments were performed in batch reactors for a single and double loads of Pd (Table 3).

The constant $k$ obtained for pristine catalytic membrane was higher than that obtained for grafted membranes. This can be explained by a difference of catalyst accessibility for the reactant, nanoparticles simply and directly adsorbed at the membrane surface would be more accessible than nanoparticles entrapped inside a polymer layer. Comparing the effect of the number of cycles, results indicated better activity with single loading. This could be explained by the difference of reactivity of the nanoparticles. The MNP presented a specific surface area of $106 \mathrm{~m}^{2} \mathrm{~g}^{-1}$ for a single load leading to greater catalytic activity $\mathrm{g}^{-1}$ MNP than with a second loading where the specific surface area was $59 \mathrm{~m}^{2} \mathrm{~g}^{-1}$.

The strategy to obtain the best catalytic efficiency should therefore be to load a large number of small diameter nanoparticles.

\subsubsection{Flow-through membrane contactor}

Reactions were performed in a flow-through membrane contactor. The solution was filtered through the membrane in a deadend filtration configuration and the permeate was analyzed after a single pass. The catalytic membrane was assimilated to a plug flow tubular reactor. Thus, assuming that the flow does not differ at the entry and at the end of the reactor, the kinetics for a first order reaction can be described as follows:

$C_{R N O_{2}}=C_{R N O_{2}} \exp (-k \tau)$ 

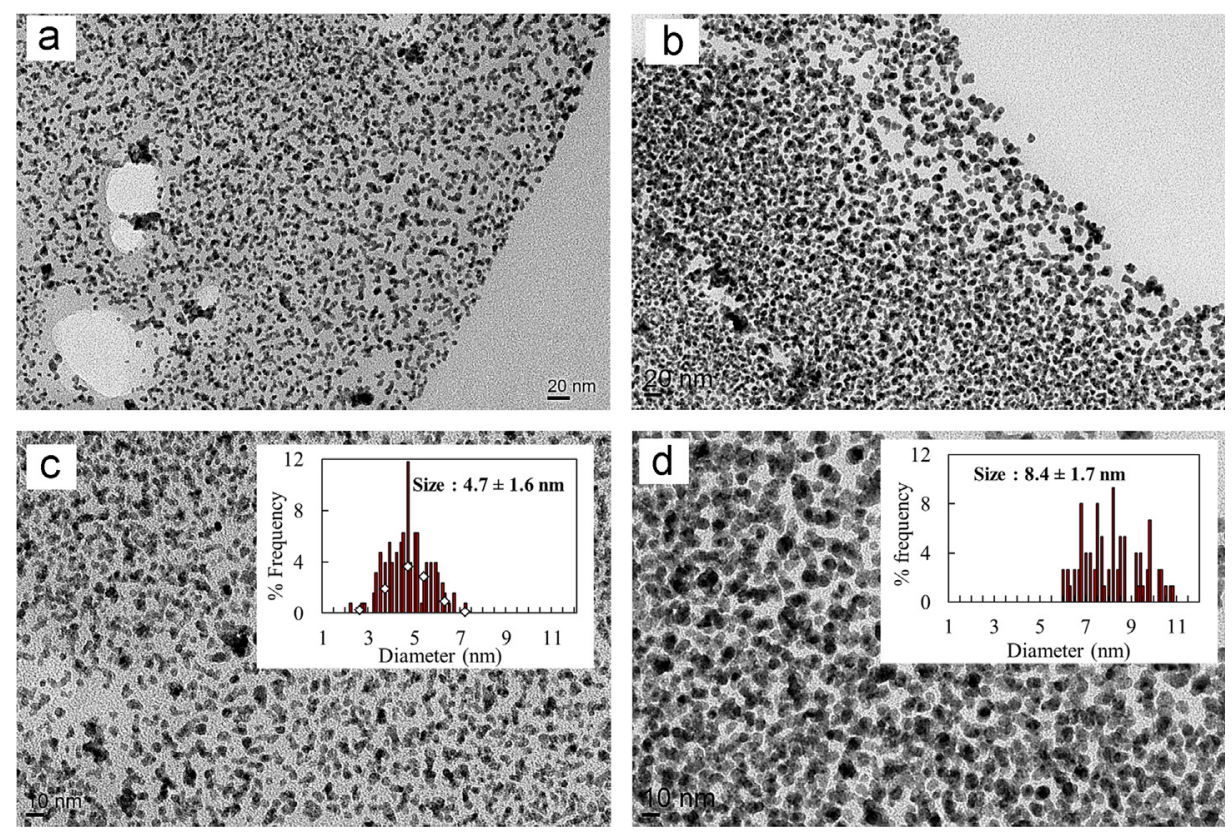

Fig. 10. TEM images of the cross section of poly(acrylic acid) grafted membrane (PES-PAA3) for a single (a) and a second loading (b) and images at higher magnification for a single (c) and a second loading (d).

Table 3

Kinetic constants $k$ obtained in batch reactor for pristine and grafted membranes with palladium nanoparticles.

\begin{tabular}{lll}
\hline Membrane & $k\left(\mathrm{~s}^{-1} \mathrm{~g}^{-1}\right)$ & \\
\cline { 2 - 3 } & Single load & Second load \\
\hline PES & 3.9 & - \\
PES-PAA1 & 2.7 & 1.8 \\
PES-PAA3 & 1.8 & 0.7 \\
PES-PAA8 & 3.6 & - \\
\hline
\end{tabular}

where $\tau$ is the residence time. In order to take into account the catalyst load, an apparent rate coefficient, $k_{a p p}$ was also defined as $k=k_{\text {app }} /$ mass of Pd.

For each experiment, the transmembrane pressure was adjusted in order to change the permeate flux and thus the residence time. For a given pressure (i.e. given residence time), the concentration was followed as a function of the time. No decrease of conversion was observed indicating a steady state but also no loss of reactivity (which can occur in the case of catalyst poisoning). Conversion of p-nitrophenol in the permeate is plotted versus permeate flux (Fig. 11). By decreasing the flow, the p-nitrophenol concentration decreased in the permeate until quasi-total conversion. The corresponding residence time was between 0.02 and $0.09 \mathrm{~s}$ in the grafted reactor layer. The curve calculated from Eq. (6), was fitted to the experimental points and an apparent rate coefficient $k$ of $84 \mathrm{~s}^{-1} \mathrm{mg}^{-1}$ was found. Compared to the value obtained on the same membrane in batch conditions ( $k$ batch $=3.6 \mathrm{~s}^{-1} \mathrm{~g}^{-1}$ ), this constant is five orders of magnitude higher. In batch conditions nanoparticles can be considered to be located in the total volume of treated solution whereas in flow through filtration, the catalyst is concentrated in the grafted polymeric layer. This high concentration enhances the kinetics and explains such a high value of $k$. It is thus possible to obtain a good conversion yield by varying the process parameters. However, an increase of the residence time involves a reduction of

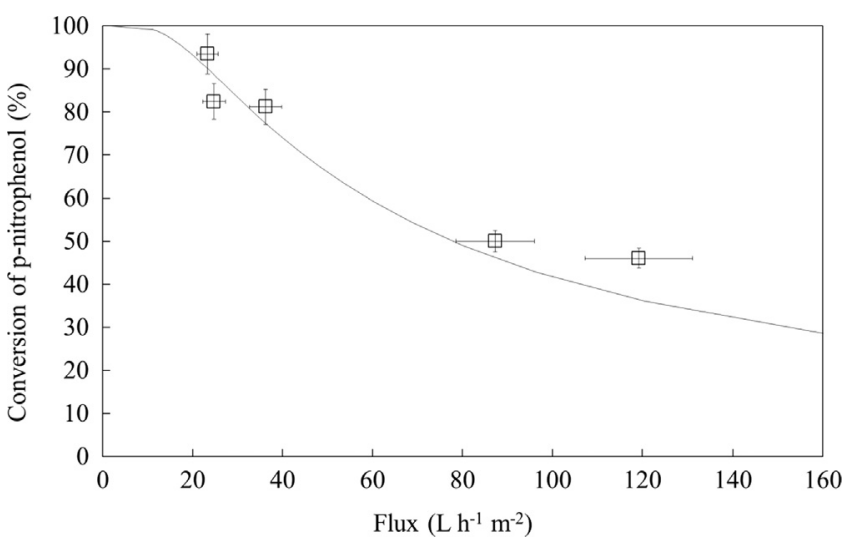

Fig. 11. Conversion of p-nitrophenol in the permeate versus the flux obtained after a single pass on PSS-PAA8 (palladium loading: $0.33 \mathrm{mg}$ ).

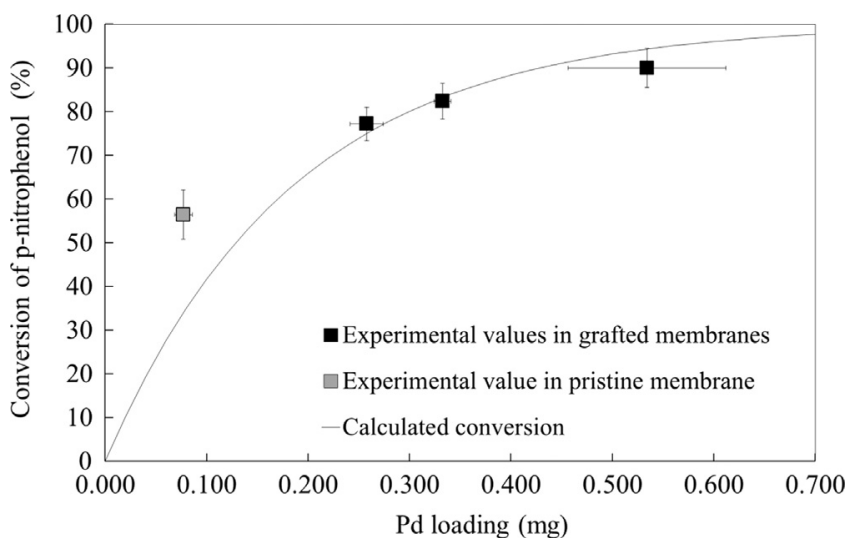

Fig. 12. Conversion of p-nitrophenol into p-aminophenol as a function of palladium loading for a pristine and for differently grafted membranes (PES, PES-PAA1, PES-PAA3, PES-PAA8). 
treated solution. Thus, for a constant flux we performed the reaction using different membranes with various thicknesses of grafted polymer.

Fig. 12 shows the conversion obtained for a pristine membrane and 3 different grafted membranes with different thicknesses and thus different catalyst loads, at identical flux kept to $28 \mathrm{~L} \mathrm{~h}^{-1} \mathrm{~m}^{-2}$. We assume that the Pd load is proportional to the reactor volume for this set of membranes, thus the reaction rate $R_{m}$ can be expressed as

$R_{m}=-Q_{v}\left(\frac{d C_{R N O_{2}}}{d m}\right)$

Consequently, the kinetics was determined as

$C_{R \mathrm{O}_{2}}=C_{\mathrm{RNO}_{2}}^{0} \exp \left(-k_{\text {app }} \frac{k_{1}}{Q_{v}} m\right)$

where $k_{1}$ is the proportionality coefficient between the volume of the reactor and the Pd loading determined as being equal to $110^{-6} \mathrm{~L} \mathrm{mg}^{-1}, m$ is the mass of catalyst in the membrane $(\mathrm{mg})$ and $Q_{v}$ is the flux expressed in $\mathrm{Ls}^{-1}$.

The conversion rate was thus seen to increase with the mass of catalyst and follows the model for grafted membranes (black squares), expressed by the calculated conversion determined by Eq. (8). The different catalytic membranes behave as a series of plug-flow tubular reactors or similar to a plug flow tubular reactors with the dimension of all grafted membrane reactors. The rate coefficient $k_{\text {app }}$ was estimated to be $36 \mathrm{~s}^{-1}$. As demonstrated before, an increase of the residence time, between 0.05 and $0.12 \mathrm{~s}^{-1}$ for this set of experiments, led to better conversion yields.

In terms of reaction rate, the second system (with variation of the reactor volume due to the different thicknesses of the grafted polymer) compared to the first system (with the variation of the flux) seems to be slightly better. In fact, we obtained, from theoretical correlation, constants equal to $36 \mathrm{~s}^{-1}$ and $28 \mathrm{~s}^{-1}$ respectively for both systems. Increasing the thickness of the grafted polymer layer could therefore be a good route for increasing the efficiency of catalytic membrane reactors.

\section{Conclusions}

Catalytically efficient hollow fibers were prepared by photografting polymerization and intermatrix synthesis. The weight of grafted polymer has a clear impact on the final property of the membrane in terms of permeability, nanoparticle loading, catalytic efficiency, and so on. Photografting was found to be a suitable tool to functionalize the membrane surface in order to incorporate MNP acting as catalyst. The greater the functionalization, the higher the MNP incorporation. However, we highlighted the presence of two different types of grafted polymer network: a partially cross-linked polymer and a chemical polymer gel and we correlated the impact of the structure of the polymer network to palladium loading. The nanoparticles created in the grafted layer are in the nanometer size range and are dispersed throughout with no aggregation. They are well trapped in the grafted layer avoiding losses due to the operating flux. The different catalytic tests show good catalytic activity for the reduction of pnitrophenol into p-aminophenol for very short residence times (lower than $0.15 \mathrm{~s}$ ). The residence time in the membrane reactor, directly connected to the conversion, can be controlled by the permeate flow but also by the thickness of the grafted layer. The hollow fiber membrane reactor can be considered as a series of plug flow tubular reactors or as a plug flow tubular reactor with the dimension of all grafted membrane reactors summed. Catalytic membrane synthesis using this versatile technique ensures the availability of various tunable materials for numerous applications, from flow-through catalytic reactors to gas/liquid contactors.

\section{Acknowledgments}

We would like to gratefully acknowledge 'Le Ministère Français de l'Enseignement Supérieur et de la Recherche' for providing a scholarship.

\section{References}

[1] N. Nady, M.C.R. Franssen, H. Zuilhof, M.S. Mohy Eldin, R. Boom, K. Schroën, Modification methods for poly(arylsulfone) membranes: a mini-review focusing on surface modification, Desalination 275 (2011) 1-9.

[2] D. He, H. Susanto, M. Ulbricht, Photo-irradiation for preparation, modification and stimulation of polymeric membranes, Prog. Polym. Sci. 34 (2009) 62-98

[3] R. Gopal, M. Zuwei, S. Kaur, S. Ramakrishna, Surface modification and application of functionalized polymer nanofibers, Top. Appl. Phys. 109 (2007) 72-92.

[4] K. Kato, E. Uchida, E.T. Kang, Y. Uyama, Y. Ikada, Polymer surface with graft chains, Prog. Polym. Sci. 28 (2003) 209-259.

[5] Y. Uyama, K. Kato, Y. Ikada, Surface modification of polymers by grafting, Adv. Polym. Sci. 137 (1998) 1-39.

[6] A. Akbari, S. Desclaux, J.C Rouch, P. Aptel, J.C. Remigy, New UV-photografted nanofiltration membranes for the treatment of colored textile dye effluents, J. Membr. Sci. 286 (2006) 342-350.

[7] M.N. Abu Seman, M. Khayet, N. Hilal, Comparison of two different UV-grafted nanofiltration membranes prepared for reduction of humic acid fouling using acrylic acid and N-vinylpyrrolidone, Desalination 287 (2012) 19-29.

[8] A.A. Abuhabib, A.W. Mohammad, N. Hilal, R.A. Rahman, A.H. Shafie, Nanofiltration membrane modification by UV grafting for salt rejection and fouling resistance improvement for brackish water desalination, Desalination 295 (2012) 16-25.

[9] H. Yamagishi, J.V. Crivello, G. Belfort, Development of a novel photochemical technique for modifying poly(arylsulfone) ultrafiltration membranes, J. Membr. Sci. 105 (1995) 237-247.

[10] M. Ulbricht, M. Riedel, U. Marx, Novel photochemical surface functionalization of polysulfone ultrafiltration membranes for covalent immobilization of biomolecules, J. Membr. Sci. 120 (1996) 239-259.

[11] S. Minko, Grafting on solid surfaces: grafting to and grafting from methods, Polym. Surf. Interfaces (2008) 215-234.

[12] P.B. Kettler, Platinum group metals in catalysis: fabrication of catalysts and catalyst precursors, Org. Process. Res. Dev. 7 (2003) 342-354.

[13] N. Wehbe, N. Guilhaume, K. Fiaty, S. Miachon, J.A. Dalmon, Hydrogenation of nitrates in water using mesoporous membranes operated in a flow-through catalytic contactor, Catal. Today 156 (2010) 208-215.

[14] D. Astruc, F. Lu, J. Ruiz Aranzaes, Nanoparticles as recyclable catalysts: the frontier between homogeneous and heterogeneous catalysis, Angew. Chem. Int. Ed. 44 (2005) 7852-7872.

[15] P. Ruiz, M. Muñoz, J. Macanás, C. Turta, D. Prodius, D.N. Muraviev, Intermatrix synthesis of polymer stabilized inorganic nanocatalyst with maximum accessibility for reactants, Dalton Trans. 39 (2010) 1751-1757.

[16] D. Astruc, Transition-metal nanoparticles in catalysis: from historical background to the state-of-the art, Nanopart. Catal. (2008) 1-48.

[17] L.F. Hakim, J.L. Portman, M.D. Casper, A.W. Weimer, Aggregation behavior of nanoparticles in fluidized beds, Powder Technol. 160 (2005) 149-160.

[18] L. Ouyang, D.M. Dotzauer, S.R. Hogg, J. Macanás, J.F. Lahitte, M.L. Bruening, Catalytic hollow fiber membranes prepared using layer-by-layer adsorption of polyelectrolytes and metal nanoparticles, Catal. Today 156 (2010) 100-106.

[19] V. Smuleac, L. Bachas, D. Bhattacharyya, Aqueous - phase synthesis of PAA in PVDF membrane pores for nanoparticle synthesis and dichlorobiphenyl degradation, J. Membr. Sci. 346 (2010) 310-317.

[20] B. Domènech, M. Muñoz, D.N. Muraviev, J. Macanás, Catalytic membranes with palladium nanoparticles: from tailored polymer to catalytic applications, Catal. Today 193 (2012) 158-164.

[21] H. Ma, Y. Geng, Y.I. Lee, J. Hao, H.G. Liu, Interfacial assembly of Pt nanoparticledoped free-standing polymer foam films and their catalytic performance, Colloids Surf. A Physicochem. Eng. Asp. 419 (2013) 201-208.

[22] J. Macanás, L. Ouyang, M.L. Bruening, M. Muñoz, J.C. Remigy, J.F. Lahitte, Development of polymeric hollow fiber membranes containing catalytic metal nanoparticles, Catal. Today 156 (2010) 181-186.

[23] S. Miachon, J.A. Dalmon, Catalysis in membrane reactors: what about the catalyst? Top. Catal. 29 (2004) 59-65.

[24] A. Akbari, S. Desclaux, J.C. Rouch, J.C. Remigy, Application of nanofiltration hollow fibre membranes, developed by photografting, to treatment of anionic dye solutions, J. Membr. Sci. 297 (2007) 243-252.

[25] A. de Ryck, D. Quéré, Inertial coating of a fibre, J. Fluid Mech. 311 (1996) 219-237.

[26] T. Goma-Bilongo, A. Akbari, M.J. Clifton, J.C. Remigy, Numerical simulation of a UV photografting process for hollow-fiber membranes, J. Membr. Sci. 278 (2006) 308-317. 
[27] R. Li, F. Joseph Schork, Modeling of the inhibition mechanism of acrylic acid polymerization, Ind. Eng. Chem. Res. 45 (2006) 3001-3008.

[28] K. Studer, C. Decker, E. Beck, R. Schwalm, Overcoming oxygen inhibition in UV curing of acrylate coatings by carbon dioxide inerting, Part I, Prog. Org. Coat. 48 (2003) 92-100.

[29] A. Michiardi, G. Hélary, P.C.T. Nguyen, L.J. Gamble, F. Anagnostou, D.G. Castner V. Migonney, Bioactive polymer grafting onto titanium alloy surfaces, Acta Biomater. 6 (2010) 667-675.

[30] D.N. Muraviev, J. Macanás, J. Parrondo, M. Muñoz, A. Alonso, S. Alegret, M. Ortueta, F. Mijangos, Cation-exchange membrane as nanoreactor: intermatrix synthesis of platinum-copper core-shell nanoparticles, React. Funct. Polym. 67 (2007) 1612-1621.

[31] A. Alonso, J. Macanás, A. Shafir, M. Muñoz, A. Vallribera, D. Prodius, S. Melnic, C. Turta, D.N. Muraviev, Donnan-exclusion-driven distribution of catalytic ferromagnetic nanoparticles synthesized in polymeric fibers, Dalton Trans. 39 (2010) 2579-2586.

[32] S. Wunder, F. Polzer, Y. Lu, Y. Mei, M. Ballauff, Kinetic analysis of catalytic reduction of 4-nitrophenol by metallic nanoparticles immobilized in spherical polyelectrolyte brushes, J. Phys. Chem. C 114 (2010) 8814-8820. 